DOI 10.37882/2223-2982.2021.05.29

\title{
ЛОГИЧЕСКИЕ ЗАДАНИЯ КАК МЕТОД ФОРМИРОВАНИЯ ЛОГИЧЕСКИХ УНИВЕРСАЛЬНЫХ УЧЕБНЫХ ДЕЙСТВИЙ И ИСТОРИЧЕСКОГО МЫШЛЕНИЯ
}

\section{LOGICAL TASKS AS A METHOD OF FORMING LOGICAL UNIVERSAL EDUCATIONAL ACTIONS AND HISTORICAL THINKING}

\section{T. Prokhorova}

Summary: The article is devoted to the study of the logical question as a method of forming universal educational actions and historical thinking. The author justifies the relevance and practical significance of the topic of research. Emphasis is placed on pedagogical potential, as well as on the problems of teaching school students the subject "History," including the problem of the formation and development of logical skills. The thesis is argued that one of the most effective methods of forming logical universal educational actions, and therefore the possibility of forming historical thinking, are logical tasks with an integrated problem approach. As a variant of such tasks, event-problem tasks are considered, examples are given.

Keywords: logical question, logical universal educational actions, historical thinking, history, logical task, event-problem tasks.
B соответствии с положениями Федерального государственного образовательного стандарта начального общего образования (ФГОС НОО) у учеников начальной школы к окончанию обучения должны быть сформированы универсальные учебные действия, составляющие т.н. «умение учиться». Именно в этой связи, одной из задач, которую ставят перед собой учителя начальных классов, в частности, на уроках истории, является развитие логической культуры младшего школьника.

Логическая культура - это, фактически, культура мышления, формирование и развитие которой предполагает овладение знаниями, умениями и навыками в области «структурирования поставленных задач, опирающееся на выделении и распределении операций, необходимых для ее разрешения», а также в области «определения уровня достаточности осуществленных разработок для обеспечения планируемого результата» [6, с. 62]. Соответственно, логическую культуру школьника следует признавать актуальной составляющей фундамента его познавательной сферы. Данный тезис подтверждается Г.В. Глинкиной и соавт., которые постулируют о том, что логические универсальные учебные действия выражены в познавательных умениях, в зна-
Прохорова Татьяна Павловна

учитель, ГБОУ города Москвы «Школа № 293 имени А.Т. Твардовского; аспирант, Московский государственный педагогический университет (МГПу)

tania524@mail.ru

Аннотация: Статья посвящена изучению логического вопроса как метода формирования универсальных учебных действий и исторического мышления. Автором обосновывается актуальность и практическая значимость темы исследования. Делается акцент на педагогическом потенциале, а также на проблемах обучения школьников предмету «История», включая проблему формирования и развития логических умений. Аргументируется тезис о том, что одним из наиболее эффективных методов формирования логических универсальных учебных действий, а следовательно возможности формирования исторического мышления являются логические задания с интегрированным проблемным подходом. Как вариант таких заданий рассматриваются событийно-проблемные задачи, приводятся примеры.

Ключевые слова: логический вопрос, логические универсальные учебные действия, историческое мышление, история, логическое задание, событийно-проблемные задания.

чительной степени обеспечивающих интеллектуальное развитие обучающихся, иными словами, логические УУД формируют мыслительные способности на основе освоения законов логики, форм мышления, логических операций и приемов [1, с. 8].

Изучение истории в начальной школе занимает особое место в формировании и развитии универсальных учебных действий, включая познавательные и их компоненту - логические УУД. Так, Н.А. Чуанова констатирует, что на уроках истории школьники учатся разделять процессы на этапы, звенья, выделять характерные причинно-следственные связи и так далее, значимые функциональные связи и отношения между частями целого, сравнивать, сопоставлять и пр. объекты по одному или нескольким предложенным основаниям, критериям, различать факты, позиции, доказательства и т.п., определять адекватные способы решения конкретных учебных задач на основе заданных алгоритмов, комбинировать их в ситуациях, не подпадающих под категорию стандартных, мотивированно отказываться от образца деятельности искать оригинальные решения [7, с. 42-43].

Соответственно, мы говорим о таких концептах, как 
1. Иван Сусанин завел в леса и болота поляков и тем самым спас жизнь Михаилу Романову. В знак благодарности царь пожаловал му-жу единственной дочери Сусанина половину дворцовой деревни «за службу и за кровь тестя его» с ос-вобождением его и его потомства от всяких податей. Почему награда досталась мужу дочери Сусанина, а не ей самой?

2. Рюриковичи во главе с Оле-гом, пришедшие из северных зе-мель, захватили Киев и убили пра-вителей города Аскольда и Дира, предварительно обманом выманив их на берег Днепра. При этом насе-ление города не оказало им ника-кого сопротивления, не защитило своих князей и подчинилось воле пришельцев. Почему?

3. Княгиня Ольга в отместку за убитого древлянами мужа дли-тельное время проявляла чудеса жестокости: закапывала живыми послов, сжигала их в бане, хит-ростью подожгла и уничтожила вместе с жителями столицу древ-лян Искоростень и т. д. И тем не менее Ольга Православной цер-ковью канонизирована. Почему? Ведь ее за содеянное, ка-залось бы, казнить мало, а тут - $е$ сеятые!

4. Почему Сеятослав, оставие стольный Киев, «хочет жить в Переяславце на Дунае»? Чем его не уст-раивал Киев?

5. В 980 г. Владимир Свято-славич делает попытку приспосо-бить языческие верования к новым условиям и на этой основе проводит языческую реформу. В Киеве ста-вятся деревянные идолы шести бо-гов во главе с Перуном, которому волосы на голове были окрашены серебром, а усы золотом. Но эта ре-форма не прижилась. Почему, ведь не новая же религия предлагалась славянам, а традииион-ная, с языческими богами?

6. Неизгладима в памяти на-родной победа русских войск на Куликовом поле в 1380 г. Но тем не менее эта победа не привела, как ожидалось, к ликвидации ига Орды. Дмитрию Донскому вскоре пришлось признать себя вассалом Тохтамыша и продолжать пла-тить дань. $B$ чем же тогда значение Куликов-ской битвы?

Рис. 1. Примеры событийно-проблемных задач по истории для обучающихся начальной школы (составлено по [4])

анализ, синтез, сравнение, классификация, сериация, подведение под понятие, вывод следствий, построение логической цепи рассуждений, выдвижение гипотез т.д. Относительно последнего положения следует сказать о том, что именно представление учителем уже готовых, логически обработанных моделей (правил, описаний, алгоритмов, тестов, заданий и пр.) с точки зрения весьма широкого спектра представителей как научного, так и педагогического сообщества является одной из причин сложности и (или) неэффективности развития логической культуры младших школьников $[6,8]$.

Делая акцент на данной проблеме В.С. Хромых и О.А. Павлова постулируют о том, что развитию логики, самостоятельности и креативности способствует обращение к нестандартным [логическим] задачам или иным обпроблематизированным [логическим] заданиям в учебной деятельности как заданиям, способ решения которых детям интересен [5, с. 94]. По Г.Н. Каменевой, логические задания по истории - это технология применения приема теоретического изучения истории, на основе познавательной деятельности обучающихся на преобразующем уровне и направленное на формирование понятий, причинно-следственных связей, закономерностей, выводов» [2].

К одному из видов таких заданий, что важно - с интегрированным в него проблемным подходом, относятся событийно-проблемные задачи. В них обычно содержатся учебные или реальные противоречия, разрешение которых требует активной мыслительной деятельности. При их разработке, как отмечает А.Т. Степанищева, всег- да берется какое-либо важно историческое событие, факт, определяется, собственно, противоречие, ему соответствующее, и, наконец, формируется т.н. логический вопрос, ориентирующий обучающегося на выработку верного ответа с обоснованием своей позиции. Вопросная часть событийно-проблемных задач традиционно начинается словами «почему», «тогда почему», «как же так», «так есть ли основание считать», «возникает вопрос», «как случилось, что» и пр. [4, с. 134]. Примерами событийно-проблемных задач могут быть следующие (см. рис.).

Избирая (разрабатывая) тот или иной комплекс событийно-проблемных задач, педагог должен учитывать возрастные и индивидуально-личностные особенности детей, а также их интересы. Данный аспект чрезвычайно важен в той связи, что история - это такой предмет, который сложно изучать без анализа различных подходов к историческим явлениям, событиям и фактам. Успешная же реализация той или иной педагогической технологии (инструмента, метода) во многом зависит от самого учителя и уровня учебной мотивации. Мы склонным полагать, что важным результатом проблемного обучения в контексте формирования и развития логических универсальных учебных действий и, соответственно, исторического мышления, является то, что обучающиеся смогут свободно ориентироваться [впоследствии] в различных современных социальных ценностях, получать опыт собственной творческой деятельности, а также, как отмечают А.И. Кондращенко и С.О. Тупикова, развить навык социализации. 
В целом, становится доказательным тот факт, что [нестандартные] логические задания, с интегрированными в них проблемными подходами, выступают актуальным методом формирования логических универсальных учетных действий и, соответственно, исторического мышления. Однако, важно понимать, что интеграция любого метода обучения в практику должна в обязательном порядке коррелировать с задачей учителя по созданию психолого-педагогических условий в целях своевременного выявления и оптимального развития способностей обучающихся, организацию разнообразной творческой, личностно и общественно значимой деятельности для формирования устойчивых и способных в дальнейшем эффективно развиваться соответствующих учебных универсальных действий.

\section{ЛИТЕРАТУРА}

1. Глинкина Г.В., Ковель М.И. и др. ФГОС: формирование и развитие познавательных универсальных учебных действий средствами Способа диалектического обучения / Г.В. Глинкина, М.И. Ковель, М.А. Митрухина, В.Л. Зорина. - Красноярск: КИПК, 2015. - 160 с.

2. Каменева Г.Н. Словарь-справочник. - Ставрополь: Изд-во СГПИ, 2009. - 63 с.

3. Кондращенко А.И., Тупикова С.О. Применение на уроках истории технологии проблемного обучения // Концепт. 2018. №V11. С. 1-5.

4. Степанищев А.Т. Методика преподавания и изучения истории: в 2 ч.: учебное пособие для студентов вузов, обучающихся по специальности 032600 «История». - М.: ВЛАДОС, 2002. - 304 с.

5. Х Хромых В.С., Павлова О.А. Методика знакомства младших школьников с нестандартными задачами на переливание // МНКо. 2021. №1 (86). С. 93-96.

6. Чиркова Н.И. Развитие логической культуры младших школьников на уроках математики // Гуманизация образования. 2017. №3. С. 61-67.

7. Чуланова Н.А. Формирование познавательных универсальных учебных действий обучающихся в урочной и внеурочной деятельности: дисс. ... канд. пед. наук: 13.00.01. - Саратов, 2017. - 224 с.

8. Шоган В.В. Методика преподавания истории в школе: учебное пособие для вузов / В.В. Шоган, Е.В. Сторожакова. - 2-е изд., перераб. и доп. - М.: Издательство Юрайт, 2020. - 433 с.

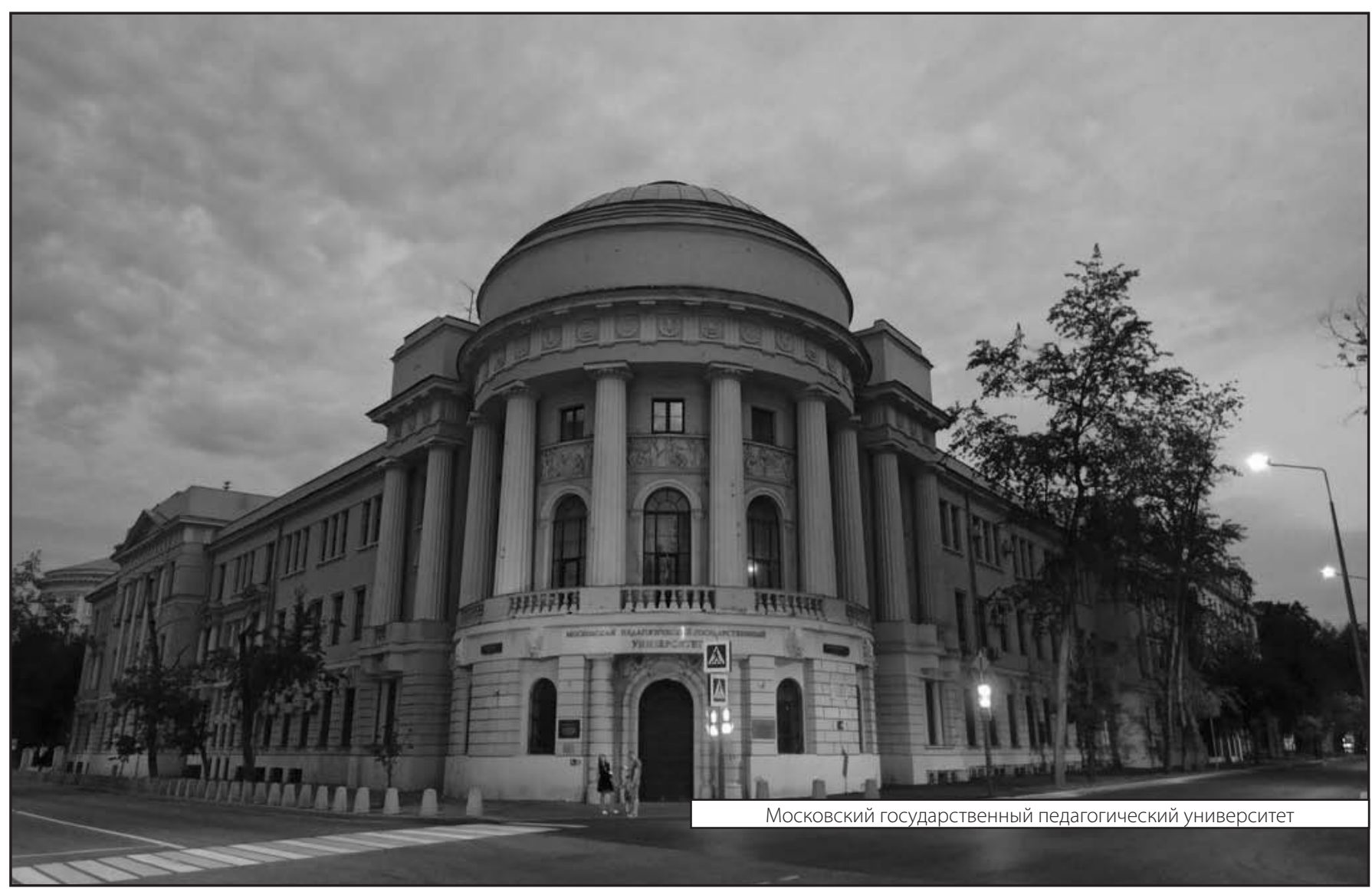

